\title{
O FALSO TRIUNFALISMO DAS DIRETRIZES PARA AS CULTURAS POPULARES NA AMÉRICA LATINA
}

Fábio Luiz Loureiro Universidade Federal do Espírito Santo

fll.cap@uol.ocm.br

Bethânia Alves Costa Zandomínegue Universidade Federal do Espírito Santo bethabill@yahoo.com.br

Rodrigo Lema Del Rio Martins Universidade Federal do Espírito Santo rodrigoefrural@hotmail.com

José Luiz Cirqueira Falcão Universidade Federal de Goiás joseluizfalcao@hotmail.com

\section{RESUMO}

Este artigo analisa as diretrizes oficiais produzidas em convenções, encontros e seminários temáticos, entre 2000 e 2017, que versam sobre a valorização e o apoio às culturas populares na América Latina. Para a realização deste estudo, foram examinados documentos relativos às temáticas da diversidade cultural e da cultura popular produzidos pela Unesco e a Carta SulAmericana de Culturas Populares. Em seguida, efetuou-se levantamento e catalogação de manifestações culturais populares, como jogos, lutas, danças e cantos, na Argentina, Bolívia, Colômbia, Venezuela, Guatemala, no Brasil, Chile, Equador, México, Peru, Uruguai e em Cuba. Posteriormente, verificou-se a presença dessas manifestações nos currículos de formação de professores de Educação Física. De posse desses dados, estabeleceu-se análise da relação entre as diretrizes, os patrimônios culturais e os currículos de formação de professores dos diferentes países, para verificar a abrangência dessas orientações nas práticas, em favor da permanência e valorização das culturas populares. Como resultado destaca-se que, apesar de as diretrizes oficiais de proteção e defesa das culturas populares se constituírem como conquistas de movimentos que lutam em favor dessas expressões, do ponto de vista operacional, isso não se efetiva. Identificou-se que a valorização das culturas populares perpassa pela desburocratização de processos que viabilizem recursos materiais para a sua salvaguarda e expansão. Da mesma forma, ficou evidente que as orientações desses documentos são ineficazes diante dos contextos de invisibilização dessas manifestações nos currículos de formação profissional, além da ausência de políticas públicas que assegurem paridade na proteção, acesso e reconhecimento dessas expressões.

Palavras-chave: Cultura popular. América Latina. Organizações multilaterais. 


\title{
FALSE TRIUMPHALISM OF GUIDELINES FOR POPULAR CULTURES IN LATIN AMERICA
}

\begin{abstract}
This article analysis the official guidelines produced in the form of declarations and letters of principles, conventions, meetings and thematic seminars on valuing and supporting popular cultures, between 2000 and 2017, in the Latin America. In order to carry out this study, we examine official documents related to the themes of cultural diversity and popular culture produced by Unesco, and the South American Charter of Popular Cultures. We then carried out the collection and cataloging of games, fights, dances, songs, etc., by us typified as popular cultures in Argentina, Bolivia, Colombia, Venezuela, Guatemala, Brazil, Chile, Ecuador, Mexico, Peru, Uruguay and Cuba. Based on these data and through content analysis, we discuss the relationship between the narratives exposed in the official guidelines, the records of national cultural heritage and the availability of professional training valuing and supporting popular cultural manifestations. As a result, we emphasize that although the official guidelines for the protection and defense of popular cultures are in some way constituted as achievements of social and cultural movements that fight for the equal recognition of cultural differences, from an operational point of view, these do not take effect. In addition, we have identified that the official guidelines produced by official organizations for popular cultures are ineffective. This is due to the lack of avenues to incorporate them in the official curriculum of professional training, and due to the absence of public policies that ensure parity in the protection, access and recognition of these expressions.
\end{abstract}

Keywords: Popular culture. Latin America. Multilateral organizations.

\section{EL FALSO TRIUNFALISMO DE DIRECTRICES PARA LAS CULTURAS POPULARES EN AMÉRICA LATINA}

\section{RESUMEN}

Este artículo aborda el análisis de directrices oficiales producidas en convenciones, encuentros y seminarios temáticos, entre 2000 y 2017, que tratan sobre la valorización y el apoyo a las culturas populares en América Latina. Para la realización de este estudio se examinaron documentos oficiales relativos a las temáticas de diversidad cultural y de la cultura popular elaborados por la Unesco y la Carta Sud-Americana de Culturas Populares. Seguidamente, se realizó la recopilación y la catalogación de juegos, luchas, danzas, cantos, etc., tipificados como culturas populares en Argentina, Bolivia, Colombia, Venezuela, Guatemala, Brasil, Chile, Ecuador, México, Perú, Uruguay y Cuba. En base a estos datos y al análisis del contenido, se discutió a cerca de la relación entre las directrices oficiales, los patrimonios culturales nacionales y otros procesos de formación profesional de valorización de las manifestaciones culturales populares. Como resultado se destaca que, a pesar de que las directrices oficiales de protección y defensa de culturas populares se consideren como conquistas de movimientos que luchan en defensa de estas expresiones, desde el punto de vista operacional esto no se llega a efectivizar. Se identificó que la valoración de las culturas populares precisa de la desburocratización de procesos que viabilicen recursos materiales para su salvaguarda y expansión. Asimismo, se identificó que las directrices oficiales son ineficaces frente a la invisibilidad de estas prácticas en los currículos de formación 
profesional, más allá de la ausencia de políticas públicas que aseguren la equidad en la protección, el acceso y el reconocimiento de estas expresiones.

Palabras clave: Cultura popular. América Latina. Organizaciones multilaterales.

\section{FAUX TRIUMPHALISME DES DIRECTRICES POUR LES CULTURES POPULAIRES EM AMÉRIQUE LATINE}

\section{RÉSUMÉ}

Cet article analyse les directives officielles produites dans les conventions, réunions et séminaires thématiques, de 2000 à 2017, qui traitent de la valorisation et du soutien aux cultures populaires en Amérique latine. Pour la réalisation de cette étude, on a été examiné des documents officiels sur le thème de la diversité culture culturelle et de la culture populaire produite par l'Unesco et la Charte Sud-Américaine de cultures populaires. Ensuite, on a été rassemblés et catalogués des jeux, des combats, des danses, des chansons etc., caractérisés comme des cultures populaires en Argentine, en Bolivie, en Colombie, au Venezuela, au Guatemala, au Brésil, au Chili, en Équateur, au Mexique, au Pérou, en Uruguay et à Cuba. Après, on a constaté la présence de ces manifestations dans les curriculums de formation de professeurs d'Éducation physique. En ce qui concerne la base de ces données et de l'analyse du contenu, la relation entre les directives officielles, le patrimoine culturel national et les processus de formation professionnelle permettent d'apprécier les manifestations culturelles populaires ont été problématiques. En conséquence, il est noté que, bien que les directives officielles pour la protection et la défense des cultures populaires soient constituées comme des conquêtes des mouvements qui se battent pour défendre ces expressions, ceci n'est pas efficace du point de vue opérationnel. En outre, on a été constaté que les directives officielles étaient inefficaces dans le contexte de l'invisibilisation de ces pratiques dans les programmes de formation professionnelle et de l'absence de politiques publiques qui garantent la parité dans la protection et la reconnaissance de ces expressions.

Mots-clés: Culture populaire. L'Amérique Latine. Organisations multilatérales.

É a América Latina, a região das veias abertas [...]. O modo de produção e a estrutura de classes de cada lugar têm sido sucessivamente determinados, de fora, por sua incorporação à engrenagem universal do capitalismo. A cada um dá-se uma função, sempre em benefício do desenvolvimento da metrópole estrangeira do momento, e a cadeia das dependências torna-se infinita [...].

(Eduardo Galeano, As veias abertas da América Latina).

\section{CONSIDERAÇÕES INICIAIS}

Quando participamos dos encontros envolvendo as cúpulas políticas nos diversos âmbitos do poder público, local, regional, nacional e internacional, somos levados a pensar que as decisões ali tomadas se concretizarão na prática, dado o caráter ostensivo desses encontros e a eloquência

Rev. Iberoam. Patrim. Histórico-Educativo, Campinas (SP), v. 5, p. 1-24, e019038, 2019. 
dos discursos. Entretanto, o aceno triunfal que emerge dos discursos em favor do reconhecimento e proteção das culturas populares acompanhados de emolduradas cartas de princípios, declarações e pactos, não se confirma na prática. É possível afirmar que tais documentos operam uma "violência fria” que, segundo Serra e Volpini (2016), é uma opressão que se manifesta sob o manto da impessoalidade concernente à burocracia estatal. Em relação às produções culturais, a violência fria se dá pela ausência da garantia de direitos e dignidade aos sujeitos organicamente envolvidos com esses processos.

Nos últimos vinte anos, algumas iniciativas oficiais entabuladas por organismos multilaterais vêm sendo realizadas na forma de convenções, declarações, pactos, seminários e encontros relacionados à valorização da diversidade cultural e à promoção das culturas populares no contexto da América Latina. Embora essas iniciativas tematizem as culturas populares e algumas possibilidades de promoção e proteção destas, são submetidas a um complexo e difuso processo institucionalizado de exclusão ou subalternização, coadjuvante do "epistemicídio" (SANTOS; MENESES, 2009) decorrente de continuidades coloniais que privilegiam determinadas epistemologias e negam ou subestimam outras. Com isso, inviabilizam uma "justiça cognitiva" (MENESES, 2009) em virtude da negação de perspectivas interculturais e da possibilidade de exercício da cidadania cultural, em relação à dimensão essencialmente pública dessa esfera.

Não defendemos que o reconhecimento e/ou a promoção das culturas populares devam emanar apenas de agentes ou fatores externos. O desafio implica, acima de tudo, na centralidade da aplicação de mecanismos institucionalizados de reconhecimento da coautoria e da coprodução de "teias de significados" (GEERTZ, 1989) levadas a cabo, pelo conjunto de atores culturais em seus diferentes campos de atuação (HENSBROEK, 2010).

Culturas populares são aqui entendidas como manifestações de dança, jogo, luta, brincadeira, celebração etc., praticadas por grupos de pessoas, no dia a dia em comunidade. Constituem expressões derivadas de acúmulos, empréstimos e transações, que amalgamam elementos imprevisíveis, oriundos de fontes socioculturais diversas, porém unificadas em uma particular e peculiar manifestação (CERTEAU, 1994).

As culturas populares contêm características que afirmam tanto a diferença entre elas como as diversificadas maneiras de ser, no seu interior. Constituem saberes que, conforme Stuart Hall (2006) são tudo, menos puros. Elementos como autenticidade, cientificidade e originalidade deixam de ser hipervalorizados para numa permanente reviravolta darem lugar a outros. Em 
síntese, culturas populares são "reminiscências duráveis" (FARIAS; MIRA, 2014), de práticas lúdico-artísticas, sagradas e/ou profanas, vivenciadas e experimentadas no cotidiano em relação interdependente com a comunidade e com o contexto envolvido.

Mais do que cultura em si, num sentido lato, as culturas populares são culturas para $\mathrm{si}^{1}$, num sentido estrito. Pelo exposto, essas práticas mescladas, sincréticas e hibridizadas tencionam “civilidade e violência; tradicionalismo e modernismo; comunitarismo e individualismo; localismo e cosmopolitismo" (FARIAS; MIRA, 2014). Seus protagonistas em situação de dominação e vinculados às camadas exploradas da população são, em tese, os principais beneficiários desse processo.

Desde a chegada dos europeus nas Américas no século XVI até o final do século XX, os intercâmbios culturais entre os povos originários constituintes das populações latino-americanas aconteceram na perspectiva da invasão e/ou do transplante cultural. Ou seja, uma determinada cultura se impunha em relação à outra. Durante aproximadamente 500 anos, o Brasil esteve alheio aos demais países da América do Sul por circunstâncias que envolveram, dentre outros fatores, o isolamento linguístico. Isso potencializou um distanciamento cultural e simbólico. Somente nos últimos anos começaram a aparecer iniciativas para diminuir essa lacuna entre os países latinoamericanos. Países que, embora próximos geograficamente, continuam muito distantes culturalmente.

Seguindo a trilha dos blocos econômicos como o NAFTA ${ }^{2}$, a América Latina compõe e agrega uma série de organismos multilaterais de cooperação regional e articulação política, dentre os quais podemos citar a Associação Latino-Americana de Integração (ALADI) ${ }^{3}$, a Comunidade e Mercado Comum do Caribe (CARICOM) ${ }^{4}$, o Sistema de Integração Latino-americano (SICA) ${ }^{5}$, a

\footnotetext{
${ }^{1}$ Segundo Carneiro da Cunha (2009), cultura "em si” e cultura "para si” não diferem significativamente, em relação aos seus conteúdos. Existem disparidades significativas entre as duas, especialmente, no que diz respeito ao discurso. Elas não pertencem ao mesmo universo discursivo e isso resulta em consequências consideráveis de espoliação do saber.

${ }^{2}$ North American Free Trade Agreement, sigla em inglês do Tratado Norte-Americano de Livre Comércio.

${ }^{3}$ Associação Latino-Americana de Integração (ALADI), maior bloco econômico da América Latina. É composta por treze países membros: Argentina, Bolívia, Brasil, Chile, Colômbia, Cuba, Equador, México, Panamá, Paraguai, Peru, Uruguai e Venezuela. Visa contribuir com a promoção da integração da região latino-americana.

${ }^{4}$ Comunidade e Mercado Comum do Caribe (CARICOM) e atual Comunidade do Caribe ou Comunidade das Caraíbas é um bloco de cooperação econômica e política assinado por Barbados, Jamaica, Guiana e Trinidad e Tobago. Entrou em vigor em 1 de agosto de 1973.

${ }^{5}$ Sistema de Integração Centro-Americano (SICA), fundado em 1991. É composto pelos países Belize, Costa Rica, El Salvador, Guatemala, Honduras, Nicarágua, Panamá e República Dominicana.
} 
União das Nações Sul-Americanas (UNASUL), o Mercado Comum dos Países do Sul $(\mathrm{MERCOSUL})^{6}$ e a Comunidade Andina $(\mathrm{CAN})^{7}$.

Além da intenção de produzir mecanismos de integração regional, esses órgãos multilaterais foram criados com o objetivo de regular as relações comerciais entres os países latinoamericanos. Ainda que os interesses precípuos desses organismos sejam de caráter político e econômico, a questão cultural encontra-se presente em seus documentos oficiais, mesmo que de forma coadjuvante.

Neste artigo procuramos identificar e analisar evidências, lacunas e tensões entre o dito e o praticado, considerando particularmente as diretrizes estabelecidas por organizações multilaterais, políticas públicas, sistemas educacionais e organizações não governamentais (ONG).

\section{ALGUNS DESDOBRAMENTOS SOBRE O DISCURSO DAS CONVENÇÕES DA UNESCO E DOS ENCONTROS SUL-AMERICANOS DE CULTURAS POPULARES}

As convenções internacionais resultam de esforços empreendidos por líderes políticos que procuram inserir as demandas particulares dos seus representados no rol das grandes questões sociais que irrompem no contexto contemporâneo. Interessa-nos, neste caso, o debate sobre a questão cultural. Em 2002, a Unesco ${ }^{8}$ produziu a Declaração Universal sobre a Diversidade Cultural, que trata a diversidade cultural como um imperativo ético, inseparável do respeito à dignidade humana e coloca a temática da diversidade cultural no mesmo patamar do respeito aos direitos humanos e às liberdades fundamentais. O discurso da Unesco enuncia uma preocupação com os direitos das pessoas pertencentes às minorias e dos povos autóctones. No referido documento, a diversidade cultural constitui-se em fator de desenvolvimento econômico e

\footnotetext{
${ }^{6}$ O Mercado Comum dos Países do Sul (MERCOSUL), criado em 1991, tem por objetivo consolidar a integração política, econômica e social entre os países que o integram, além de fortalecer os vínculos entre os cidadãos do Bloco e contribuir para a melhoria da qualidade de vida dos seus integrantes. É composto atualmente pelos seguintes países: Argentina, Brasil, Paraguai, Uruguai e Venezuela - na condição de Estado Parte. A Bolívia encontra-se, desde 2012 , em processo de adesão à condição de Estado Parte. Estados Associados: Chile, desde 1996; Peru, desde 2003; Colômbia e Equador, desde 2004; Guiana e Suriname, desde 2013.

7 Comunidade Andina (CAN) é um bloco econômico sul-americano surgido em 1969. É formado por Bolívia, Colômbia, Equador e Peru.

${ }^{8}$ Organização para a Educação, a Ciência e a Cultura das Nações Unidas. Organismo criado em 1946, com o objetivo de globalizar a educação, definir e proteger o Patrimônio da Humanidade Cultural ou Natural, dentre outros. Ver em: http://www.brasilia.unesco.org. Acesso em: 3 mar. 2018.
}

Rev. Iberoam. Patrim. Histórico-Educativo, Campinas (SP), v. 5, p. 1-24, e019038, 2019. 
patrimônio comum da humanidade (UNESCO, 2007). É plausível assegurar que a Unesco procura, com isso, enfrentar os abissais processos de dominação decorrentes do colonialismo, dentre eles:

A dominação epistemológica, uma relação extremamente desigual de saber-poder que conduziu à supressão de muitas formas de saber próprias dos povos e/ou nações colonizados. As epistemologias do Sul são o conjunto de intervenções epistemológicas que denunciam essa supressão, valorizam os saberes que resistiram com êxito e investigam as condições de um diálogo horizontal entre conhecimentos. A esse diálogo entre saberes chamamos ecologia dos saberes (SANTOS; MENESES, 2009, p. 12-13).

Em outubro de 2005, a Unesco realizou em Paris a Convenção sobre a Proteção e Promoção da Diversidade das Expressões Culturais, que elevou, pela primeira vez, a cultura a um novo patamar, ao inserir a diversidade cultural no ordenamento jurídico internacional. A partir dessa Convenção, estabeleceram-se oito princípios diretores sintonizados com a pauta dos direitos sociais, individuais e com um específico conceito de cidadania, quais sejam: 1) Princípio do respeito aos direitos humanos e às liberdades fundamentais; 2) Princípio da soberania; 3) Princípio da igual dignidade e do respeito por todas as culturas; 4) Princípio da solidariedade e cooperação internacionais; 5) Princípio da complementaridade dos aspectos econômicos e culturais do desenvolvimento; 6) Princípio do desenvolvimento sustentável; 7) Princípio do acesso equitativo; e 8) Princípio da abertura e do equilíbrio (UNESCO, 2007).

A análise desses princípios nos permite identificar uma ênfase nos processos de cooperação, acessibilidade e respeito à diversidade cultural. Conforme a Convenção, “[...] a diversidade cultural, ao florescer em um ambiente de democracia, tolerância, justiça social e mútuo respeito entre povos e culturas é indispensável para a paz e a segurança no plano local, nacional e internacional" (UNESCO, 2007, p. 1).

A realização de uma Convenção da Unesco com o objetivo de proteger e promover a diversidade das expressões culturais advém, entre outros aspectos, de lutas que foram empreendidas em favor do enfrentamento do processo de colonização cultural. A Convenção pode ser também vista como uma tática de enfrentamento à indústria do entretenimento empreendida desde o início do século XX, com a supremacia de artefatos culturais europeus, norte-americanos e chineses. O texto final da Convenção atesta persuasivamente, a "vitória dos Estados" que, em sua construção, “[...] lutaram por fazer prevalecer a visão de que os bens culturais, expressivos de identidades e valores sociais, possuem natureza especial e excepcional ao rol de serviços e produtos meramente comerciais" (ROIZMAN, 2014, p. 141). 
A Convenção foi ratificada no Brasil por intermédio do Decreto Legislativo $n^{o}$ 485/2006 e se alinhou com os aparatos legais concernentes aos direitos culturais estabelecidos, tanto universalmente, quanto nacionalmente. No primeiro caso, por intermédio da Declaração Universal dos Direitos Humanos ${ }^{9}$, de 1948, em seu artigo $27^{10}$ (ONU, 2016). No segundo caso, por meio dos artigos 215 e 216 da Constituição Federal de 1988, que tratam, especificamente, da questão cultural (BRASIL, 1988).

Outros órgãos da ONU também já tomaram iniciativas em relação à valorização e à proteção das manifestações culturais. Destacamos a criação, em 2001, de um Comitê Intergovernamental para a Proteção da Propriedade Intelectual, Recursos Genéticos, Conhecimento Tradicional e Folclore, pela Organização Mundial da Propriedade Intelectual (OMPI), com sede em Genebra, Suíça. A OMPI, fundada em 1967, constitui uma das dezesseis agências especializadas da ONU e é responsável por estimular a proteção da propriedade intelectual (ONUBR, 2016).

Essas inciativas acerca da questão cultural entabuladas pela ONU e seus organismos constitutivos demonstram a importância da cultura na construção de uma nova ordem planetária, envolvendo a esfera da cidadania e dos direitos humanos. Entretanto, apenas em 2006, pela primeira vez, foram garantidas, na América Latina, condições materiais propícias para a promoção de intercâmbios diretos e reconhecimentos mútuos entre os mestres das culturas populares representantes de diversos países no I Encontro Sul-Americano das Culturas Populares e II Seminário Nacional de Políticas Públicas para as Culturas, realizados em Brasília. Durante esse encontro, o mestre Salustiano do Maracatu pernambucano propalou:

Eu nunca imaginei e queria que meus antepassados fossem vivos para ver aonde a cultura popular chegou. Em 1989, o Maracatu era bem pouco desenvolvido e eu decidi vender uma caminhonete para criar uma associação. Aí veio a doidice danada, já que são difíceis essas coisas. Mas só se colhe se plantar e acreditar. Eu acreditei na minha vida e na cultura popular e sabia que um dia teria valor. Como prova, estão aqui hoje 27 Estados do Brasil e mais os países estrangeiros, discutindo cultura popular. (ENCONTRO..., 2007, p. 33).

\footnotetext{
9 A Declaração Universal dos Direitos Humanos (DUDH) foi traduzida para mais de trezentos e sessenta idiomas (ONU, 2016).

${ }^{10} \mathrm{O}$ artigo 27 é composto de dois itens: 1 . Todo ser humano tem o direito de participar livremente da vida cultural da comunidade, de fruir as artes e de participar do processo científico e de seus benefícios. 2. Todo ser humano tem direito à proteção dos interesses morais e materiais decorrentes de qualquer produção científica, literária ou artística da qual seja autor (ONU, 2016).
}

Rev. Iberoam. Patrim. Histórico-Educativo, Campinas (SP), v. 5, p. 1-24, e019038, 2019. 
A fala do Mestre Salustiano deixa evidente o quanto os saberes produzidos no contexto das classes populares continuam, em certa medida, invisibilizados e desprovidos de políticas públicas de promoção de direitos, quando comparados aos conhecimentos classicamente considerados como eruditos. A análise dessa questão mostra a emergência de uma "sociologia das ausências" (SANTOS, 2002) que elucide as estruturas epistemológicas coloniais responsáveis pela edificação de uma matriz hegemônica que se manifesta, tanto nos tratados de caráter jurídicopolítico, quanto nos clássicos literários e científicos que lhe dão suporte. Nesse contexto, não se trata de uma inclusão pura e simples de práticas e saberes populares, mas principalmente da desconstrução dos discursos que posicionaram as culturas populares numa condição marginal ou subalterna.

Em 2008, ocorreu na Venezuela o II Encontro Sul-Americano das Culturas Populares, onde foi redigida a Carta Sul-Americana das Culturas Populares ${ }^{11}$ por representantes das delegações dos países participantes (Argentina, Bolívia, Brasil, Equador, Paraguai, Venezuela e Cuba). A Carta propôs, dentre outros, a criação de um fundo latino-americano de proteção e promoção das culturas populares; a elaboração de políticas de gestão de riscos dessas expressões; a criação de centros de formação permanente e, com isso, a efetivação do "[...] casamento entre educação e cultura" (CARTA SUL-AMERICANA, 2008, p. 3) e chamou a atenção dos governos e da população em geral para a valorização das culturas populares como expressões que constituem “[...] a alma, o passado, o presente e o futuro" dos povos (CARTA SUL-AMERICANA, 2008, p. $1)$.

Esses eventos contribuíram para uma mudança de perspectiva, na forma como os países da América do Sul consideravam suas tradições culturais populares. As trocas interculturais centradas nessa temática envolvendo os brasileiros e os vizinhos sul-americanos, até então, eram escassas e empreendidas por meio de inciativas privadas e pontuais. Contudo, consideramos que um trato genérico às culturas populares em relação aos saberes mais valorizados socialmente não garante proteção às suas especificidades. Ao contrário, tornam-nas ainda mais suscetíveis ao enfraquecimento ou extinção. Nesse sentido, as diferenças não devem ser negligenciadas em benefício da igualdade das ações, sem que sejam reconhecidos os contextos particulares das produções.

\footnotetext{
${ }^{11}$ Constitui o primeiro manifesto sul-americano em defesa das culturas populares redigido conjuntamente e a partir
} das vozes dos próprios mestres e artistas das expressões culturais tradicionais da América Latina. 
Sobre essa questão, não defendemos uma proteção geral e abstrata dessas culturas no sentido de igualá-las em importância em relação aos outros saberes. Ao contrário, propomos que haja o reconhecimento das pessoas em seus grupos como sujeitos de direitos e produtoras de culturas, com tratamento e proteção particularizados, conforme suas vulnerabilidades e produções específicas.

Para Santos (2003, p. 56), as diferenças devem ser aniquiladas quando se trata da promoção de direitos.

Temos o direito a ser iguais quando a nossa diferença nos inferioriza; e temos o direito a ser diferentes quando a nossa igualdade nos descaracteriza. Daí a necessidade de uma igualdade que reconheça as diferenças e de uma diferença que não produza, alimente ou reproduza as desigualdades.

Desse modo, consideramos que os tratados e princípios anunciados nesses encontros que abrangeram inclusive, a esfera do direito, acenam para uma necessária articulação entre as políticas públicas, os sistemas educacionais e as ONGs, de modo a estabelecer uma relação de complementariedade recíproca entre os campos político, educacional e cultural.

\section{INICIATIVAS DE INTEGRAÇÃO CULTURAL NA AMÉRICA LATINA}

Antes dos eventos destinados ao intercâmbio das culturas populares de países sulamericanos, algumas iniciativas com o objetivo de promover a integração cultural latino-americana já tinham sido realizadas. Uma das primeiras iniciativas oficiais a envolver a integração do Brasil com países latino-americanos ocorreu em 1989, com a realização do Festival Latino-Americano de Arte e Cultura (FLAAC), organizado pela Universidade de Brasília. O FLAAC contou com mesasredondas, shows de música, teatro, exposições e oficinas para a troca de experiências entre mestres e praticantes das culturas populares de vários países latinos.

Em 2002, ocorreu na cidade de Coro, Venezuela, um Encontro das Culturas AfroAndinas, considerado um marco histórico por reunir grupos da Bolívia, Peru, Equador, Colômbia e Venezuela que, até então, não haviam compartilhado, presencialmente, suas artes e saberes populares.

$\mathrm{Na}$ esteira dessas possibilidades de integração intercultural, algumas ações de grande significado político e simbólico foram empreendidas, como, por exemplo, a realização da II 
Conferência dos Intelectuais Africanos e da Diáspora (II CIAD), em 2006, em Salvador/BA. Esse evento contou com a presença do Secretário Geral das Nações Unidas, de vários chefes de Estado e reuniu cerca de 1000 intelectuais africanos e da diáspora e colocou o Brasil como sede da Diáspora Africana no mundo.

Outro evento que fomentou essa mudança de perspectiva em relação a integração cultural latino-americana foi a Conferência Regional das Américas: sobre avanços e desafios no plano de ação contra o racismo, a discriminação racial, a xenofobia e as intolerâncias correlatas, realizada em 2006, em Brasília. Essa Conferência foi organizada pela Secretaria Especial de Políticas de Promoção da Igualdade Racial (SEPPIR) do governo brasileiro, em parceria com o Chile e o apoio do Alto Comissariado das Nações Unidas. Contou com representantes governamentais de 21 países das Américas e teve, como objetivo, debater as políticas de combate ao racismo. O evento trouxe, como pano de fundo, as proposições do plano de ação da III Conferência Mundial de Combate ao Racismo, Discriminação Racial, Xenofobia e Intolerância Correlata, realizada em Durban, África do Sul, em 2001.

Esses dois encontros internacionais tiveram como objetivo reconectar o Brasil com as suas origens africana e indígena. Ambos contribuíram para alçar o país como um dos pioneiros, na Campanha de Promoção e Proteção da Diversidade das Expressões Culturais. Essa campanha foi iniciada na Convenção sobre a Promoção e Proteção da Diversidade das Expressões Culturais, ocorrida em Paris, em 2005, cujo objetivo consistiu em incentivar as nações do mundo a promover e assegurar a sua diversidade cultural, praticada por seus povos, grupos étnicos e comunidades (UNESCO, 2007).

Apesar das iniciativas empreendidas pelas convenções e conferências acerca das questões culturais, não houve uma reverberação efetiva dos postulados arrolados nos documentos produzidos nos países envolvidos. As ações e as políticas desses países nem sempre incorporaram os princípios defendidos pelos organismos multilaterais em favor da promoção e valorização da diversidade cultural. Em geral, as políticas culturais e educacionais terminam reféns do movimento da indústria cultural e da circulação de mercadorias em suas dimensões étnicas e educacionais. O fracasso dessas iniciativas é indicado pelo silenciamento ou a exclusão arbitrária das historicidades e das formas de expressão das culturas populares latino-americanas no contexto formal de educação dos países desse bloco. 
Em estudo recente que versa sobre a presença das culturas populares na formação profissional em Educação Física na América Latina, Falcão et al. (2017) confirmam essas ausências e exclusões arbitrárias nos currículos dos cursos de formação. Para os referidos autores,

Se, por uma série de razões, a Educação Física nesses países é hegemonicamente herdeira de epistemes europeias e norte-americanas, que se desejam universais, urge reconstruir uma Educação Física latino-americana que dialogue de forma mais orgânica com saberes/fazeres locais frequentemente invisibilizados pelo manto de uma pseudo-universalidade. [...] Se Futebol, Basquete, Voleibol, Rugby, Hockey etc., aparecem na maioria das grades curriculares, às vezes em mais de duas disciplinas, por que não aparecem Pato, Resfalosa, Juego del Palin, Joropo, Karabotas? (FALCÃO et al., 2017, p. 23-24).

Em relação ao reconhecimento da Unesco de que as comunidades tradicionais e especialmente as indígenas desempenham um papel preponderante na produção, manutenção e recriação do patrimônio cultural imaterial ao redor do mundo, percebemos que este não tem sido suficiente para assegurar a valorização/proteção dos saberes produzidos por essas comunidades. A escassez de políticas públicas para o setor demonstra que não basta o reconhecimento de uma entidade como a Unesco, ainda que seja portadora de prestígio histórico de alcance universal. Não obstante, o reconhecimento deve implicar na superação da subordinação social e não se restringir apenas à dimensão identitária. Este deve abarcar, especialmente, as condições materiais de participação na vida social (FRASER, 2010).

A tentativa fracassada de criação da Universidade (Pública) da Floresta, em 2003, na cidade de Cruzeiro do Sul, no Acre, que projetava novas formas de relação entre conhecimentos tradicional e científico (RANZI, 2007), demonstra que muitas ideias já foram aventadas em favor da valorização dos saberes populares, mas não sobreviveram, em virtude da ausência de políticas públicas que fornecessem condições materiais de existência e manutenção para essas iniciativas.

Uma das alternativas utilizadas desde 2003 pela Unesco para promover e valorizar as manifestações culturais populares ao redor do mundo é o seu registro como patrimônio cultural imaterial da humanidade. Algumas expressões vinculadas às culturas populares e aos saberes tradicionais na América Latina já foram registradas como patrimônio cultural imaterial. Por exemplo, o samba de roda do recôncavo baiano (2008), o frevo pernambucano (2012), a procissão do Círio de Nazaré, de Belém (2013) e a capoeira (2014), no Brasil; o El Candombe (2009), no Uruguai; a La Charrería (2016), no México; o El Carnaval de El Callao (2016), na Venezuela; a La tumba francesa (2008) e a La Rumba (2016), em Cuba; o El Vallenato (2005), na Colômbia; La 
Tijeras (2010) e La danza del Wititi (2015), no Peru; La Marimba (2015), no Equador e na Colômbia; o El Baile Chino (2014), no Chile; o El Pujllay y El Ayarichi da cultura Yampara (2014), na Bolívia (UNESCO, 2018) ${ }^{12}$.

Entretanto, se o registro oficial dessas manifestações culturais populares não vir acompanhado de uma eficiente e permanente política de salvaguarda por parte dos poderes públicos, o desejo de promovê-las e valorizá-las não sairá do discurso textual. O registro da roda de capoeira do Brasil como patrimônio cultural imaterial da humanidade, na $9^{a}$ Sessão do Comitê Intergovernamental para a Salvaguarda realizada em 2014, em Paris, pela Unesco, demonstra que não basta um órgão, ainda que 'poderoso', reconhecer a importância desse bem.

Até o presente momento não foram implementadas diversas ações arroladas pelo Instituto do Patrimônio Histórico e Artístico Nacional (IPHAN) no seu plano de salvaguarda. A exemplo, destacamos: a) a elaboração de um plano de previdência especial para os velhos mestres; b) o estabelecimento de um programa de incentivo desta manifestação no mundo; c) a criação de um Centro Nacional de Referência da Capoeira e; d) a elaboração de um plano de manejo da biriba (reconhecidamente uma das madeiras mais adequadas para a confecção de berimbaus) (IPHAN, 2008).

Cabe ainda sublinhar que interesses difusos e corporativos vinculados ao grande capital podem distorcer o significado das políticas de patrimônio cultural. Segundo Castro-Gómez (2005), a salvaguarda do conhecimento tradicional se transformou em importante fiadora do chamado 'desenvolvimento sustentável'. Conforme o autor, o risco consiste em disponibilizar esse corpus de conhecimentos tradicionais milenares, utilizados por centenas de comunidades ao redor do mundo, em poder de agências multinacionais especializadas para patenteá-los, dada suas múltiplas possibilidades de comercialização. Por outro lado, algumas manifestações culturais populares compõem a lista da Unesco como culturas imateriais que requerem medidas urgentes de salvaguarda para que não sejam extintas, como é o caso do ritual Iaõkwa, dos índios Enawene Nawe do Brasil (UNESCO, 2017).

No contexto do capitalismo global, o processo de produção é pautado por relações transculturais, tendo o conhecimento como principal força produtiva que substitui o trabalho físico e material da indústria (HARDT; NEGRI, 2005). De acordo com os autores, a força de trabalho é constituída por agentes capazes de produzir e administrar conhecimentos, de modo que os bens

${ }^{12}$ Disponível em: http://www.unesco.org/culture/ich/es/listas. Acesso em: 20 out. 2018. Rev. Iberoam. Patrim. Histórico-Educativo, Campinas (SP), v. 5, p. 1-24, e019038, 2019. 
imateriais passam a ser vinculados e dependentes das tecnologias de comunicação. No entanto, como essas tecnologias geralmente são patenteadas e controladas por grandes corporações, há o risco iminente desses saberes se tornarem reféns de interesses distintos daqueles que os produziram. A potencialização do 'capital humano' é necessária ao processo de desenvolvimento e deve estar sintonizada com demandas contemporâneas pautadas na equidade, soberania, respeito às diferenças e democratização dos direitos sociais para os povos tradicionais.

Diante dessas considerações, a valorização das práticas culturais populares na América Latina e no mundo perpassa pela sua inserção na esfera do direito e da educação. Isso implica uma articulação entre acordos firmados em convenções internacionais, políticas públicas intersetoriais, locais, regionais, nacionais e transnacionais. E, da mesma forma, entre sistemas educacionais e ONGs, numa interrelação de complementariedade recíproca entre diversos campos.

Em síntese, destaca-se que já existe, ainda que não ostensivamente, um debate teórico acerca da relação entre saberes locais e globais na perspectiva da "descolonialidade". Tal como destaca Mignolo (2003), sem negar a importância da ciência e das formas de saberes ocidentais hegemônicas, a perspectiva da descolonialidade 'regionaliza' e 'provincializa' as diferentes histórias locais em sua tensa relação com projetos globais. Afinal, como disse Fraser (2010, p. 115), a luta pelos direitos humanos internacionais deve "[...] promover tanto o respeito universal pela humanidade compartilhada, como a estima pela distinção cultural”.

\section{A Diversidade CULTURAL E AS CULTURAS POPULARES NO CONCRETO VIVIDO DOS PAÍSES DA AMÉRICA LATINA E SUAS REVERBERAÇÕES INSTITUCIONAIS}

Neste tópico apresentaremos a diversidade de práticas referenciadas como culturas populares nos 12 países da América Latina ${ }^{13}$. Faremos isso em forma de quadro expositivo (Quadro 1) para favorecer a visualização da diversidade e abrangência das manifestações oriundas das culturas populares nesses locais. Posteriormente, analisaremos a relação entre os patrimônios

\footnotetext{
${ }^{13}$ A escolha desses países se deu mediante à adesão voluntária de pesquisadores residentes nesses locais, ao estudo matricial desenvolvido desde 2013, pela Universidade Federal de Goiás, intitulado Análise comparativa do perfil da formação profissional em Educação Física: a América Latina em foco, sob a coordenação da professora Ana Márcia Silva.
} 
culturais, as diretrizes e os currículos de formação de professores dos diferentes contextos estudados.

Para a coleta e a organização dos dados, identificados por meio de pesquisa com o uso de termos chaves, o auxílio da internet e dos softwares Nvivo e WebQDA, contamos com o auxílio dos estudantes da disciplina Tópicos Especiais em Educação Física e Cultura Popular na América Latina $^{14}$.

A construção de sínteses explicativas ocorreu a partir de problematizações e análises de conteúdo (BARDIN, 1977) das resoluções estabelecidas nas convenções dos organismos multilaterais, cartas de princípios e outros dispositivos legais relativos às manifestações culturais populares. Também efetuamos análises dos desdobramentos e impactos concernentes à promoção e proteção das culturas via processos de escolarização, registros como patrimônios culturais nacionais, inserção em currículos de formação profissional, adoção de políticas públicas e estratégias de democratização da sociedade civil.

QUADRO 1 - Manifestações culturais populares de países latino-americanos

\begin{tabular}{|c|l|}
\hline Países da América Latina & \multicolumn{1}{|c|}{ Manifestações Culturais Populares } \\
\hline Argentina & $\begin{array}{l}\text { Candombe; Chacarera; Chamamé; Cielito; El gato; El marote; } \\
\text { Malambo; Pala pala; Pato; Pericón; Polito; Tango; Zamba }\end{array}$ \\
\hline Chile & $\begin{array}{l}\text { Cachimbo; Cosecha; Cueca Chilota; Cueca Nortina; Juego del Palin; } \\
\text { Mazamorra; Pequén; Pericona; Repicao; Resfalosa; Sajuriana; } \\
\text { Trastasera; Trote }\end{array}$ \\
\hline Colômbia & $\begin{array}{l}\text { Bambuco; Champeta; Cumbia; Currulao; El garavato; El porro; El } \\
\text { torbellino; Esgrima com machete; Fandango; Joropo; La chicha; La } \\
\text { guabina; Mapalé }\end{array}$ \\
\hline Peru & $\begin{array}{l}\text { Babu; Bacon; Festejo; Dança de tijeras; Diablada; El huaylash; } \\
\text { Huayano; Karabotas; La chonginada; Marinera; Negroide lama; } \\
\text { Resbalosa; Tondero; Vals crioulo; Zamacuenca }\end{array}$ \\
\hline Uruguai & Lhamadas; Candombe; Murga \\
\hline Bolívia & $\begin{array}{l}\text { Brincau; Caporales; Carnavalito; Chovena; Chutas; Diablada; } \\
\text { Kullawada; Llamerada; Macheteros; Morenada; Potolos; Taquirari; } \\
\text { Tinku }\end{array}$ \\
\hline Equador & $\begin{array}{l}\text { Bomba del chota; Capishca; El albazo; El cachullapi; El pasillo; El } \\
\text { yumbo; La mama negra; La tonada; Pasacalle; San juanito; Marimba }\end{array}$ \\
\hline Venezuela & \begin{tabular}{l} 
Garrote; Joropo \\
\hline Guatemala
\end{tabular} \\
\hline México & $\begin{array}{l}\text { Chichicastenango; Marimba } \\
\text { Parachicos; Guelagueza }\end{array}$ \\
\hline &
\end{tabular}

${ }^{14}$ Disciplina ofertada por José Luiz Cirqueira Falcão como atividade integrante do Estágio de Pós-Doutoramento, no Programa de Pós-Graduação em Educação Física - PPGEF/CEFD/UFES, no segundo semestre de 2016. 


\begin{tabular}{|c|l|}
\hline Cuba & $\begin{array}{l}\text { Bembe; Guaguancó; Guaracha; Mambo; Mani ou Bombosa; Perico } \\
\text { ripiao; Punto; Rumba; Salsa }\end{array}$ \\
\hline \multirow{2}{*}{ Brasil } & $\begin{array}{l}\text { Coco de roda; Jongo; Huka huka; Frevo; Maculelê; Maracatu; } \\
\text { Capoeira; Boi de mamão; Catira; Cavalo marinho; Luta marajoara; } \\
\text { Samba de roda; Tambor de crioula }\end{array}$ \\
\hline
\end{tabular}

Fonte: Os autores.

Um traço comum observado nesse levantamento das culturas populares presentes nos países latinos investigados é o fato de essas manifestações constituírem-se como espaços e movimentos da sociedade civil. Embora algumas dessas práticas estejam articuladas a contextos locais ou a matrizes multinacionais, como ONGs, fundações e institutos, todas constituem, amiúde, espaços únicos, talvez exclusivos, para a afirmação e/ou contestação cultural e política. Além de suas características intrínsecas como instâncias da sociedade civil, as manifestações oriundas das culturas populares constituem-se como arenas de lutas que problematizam relações de poder, racismo, sexismo, discriminação e exclusão social.

A diversidade dessas manifestações na América Latina é, sem dúvida, muito maior que o exposto no quadro anterior. Na Colômbia, por exemplo, o folclorista Guillermo Abadía Morales (1983) catalogou, em seu compêndio sobre o folclore, 211 cantos e ritmos nativos e os classificou por nome, características e povo indígena envolvido. No Chile, existe uma série de manifestações culturais, até hoje praticadas, que se remetem aos povos que já se encontravam no território desse país antes da chegada dos espanhóis, tais como o Juego del Palin, originário do povo Mapuche que, como a Capoeira no Brasil, também já foi proibido, mas que, desde 2004, tornou-se esporte nacional (TORREALBA, 2012).

No Peru foram catalogadas cerca de 3 mil festas populares por ano. Nesse país existe um dos dez idiomas mais raros do mundo, o Taushiro, uma língua nativa falada na região do rio Tigre. Aqueles que falavam a língua normalmente, só sabiam contar numericamente até dez. Em 2008, um estudo da Sociedade Linguística Internacional concluiu que apenas uma pessoa falava esse idioma fluentemente (SIL INTERNACIONAL, 2009). Cabe ressaltar ainda que, as manifestações culturais do Peru recebem grande influência de sua divisão geográfica. O folclore por exemplo, é dividido em costeiro, andino e amazônico.

A Bolívia é marcada por danças que, de maneira geral, caracterizam-se por teatralizar acontecimentos históricos e identitários dos povos tradicionais e das regiões onde elas predominam. Outra característica são as indumentárias, ricas em cores e sentidos, que ajudam na 
expressão teatral. Cada manifestação dançante está intimamente ligada a um Departamento ${ }^{15}$ boliviano e dialoga com as questões peculiares dessas regiões (climáticas, geográficas, étnicas). Conforme Silva (2016, p. 77), “[...] a diversidade de danças típicas expressa elementos de um passado sociocultural evocado, às vezes, de forma mítica e, uma vez reproduzidas no contexto de imigração, passam a veicular identidades culturais ou étnicas”.

Embora muitas manifestações tipificadas como culturas populares na América Latina tenham sido invisibilizadas por questões religiosas e coloniais, ainda hoje elas continuam a resistir aos processos de dominação cultural, seja como tradição de determinado povo originário ou processos de patrimonialização efetuados pelos seus respectivos Estados. Resistem ainda, por intermédio de movimentos diaspóricos, que promovem circuitos comunicativos capazes de levar populações dispersas a interagir, criar e até sincronizar elementos culturais significativos, por meio de combinação, tangenciamento e suplementaridade de seus modos de fazer.

Talvez por essa razão seja difícil delimitar a que país/região pertence determinada prática cultural. Existem disputas entre países para patentear danças, jogos, lutas, como típicas de seu povo/cultura. Um exemplo, é a reclamação formal da Bolívia em relação ao uso de algumas danças folclóricas como a Morenada, o Caporales e o Tinku ${ }^{16}$ em um vídeo de promoção turística do Chile. Isso expõe uma fragilidade quanto à tentativa de enquadramento das manifestações pelos países, em detrimento do seu reconhecimento como herança e construção permanente, de povos e grupos sociais que extrapolam a noção de territorialidade contemporânea.

A história da humanidade está cheia de episódios colonizadores. Por interesses econômicos, os espaços geográficos são delimitados sem que haja consideração às questões étnicas ${ }^{17}$. Nesse quesito, a própria Bolívia sofreu muito com anexações ${ }^{18}$ e disputas de seus territórios pelos seus vizinhos Brasil, Peru e Chile.

Se tomarmos como referência esse diagnóstico preliminar, veremos que existe uma diversidade de práticas corporais materializadas na forma de danças, jogos e lutas oriundas das culturas populares desses países. O levantamento, sempre inacabado, das práticas culturais, leva-

\footnotetext{
${ }^{15}$ Unidade territorial geográfica equivalente aos Estados brasileiros.

16 Ver mais em: http://www.eabolivia.com/politica/23273-bolivia-denuncia-a-chile-por-usar-danzas-tipicas-ywiphala-en-video-promocional-turistico.html. Acesso em: 28 nov. 2018.

${ }_{17}$ Um exemplo é a colonização europeia da África, fato que gera problemas bélicos e distorções econômicas até hoje.

${ }^{18} \mathrm{O}$ estado do Acre pertencia à Bolívia, até 1903 e foi anexado ao território do Brasil por meio de uma "compra" por 200.000 libras esterlinas. Em 1866 o Chile anexou uma importante região costeira e rica em minerais. Em 1909, a Bolívia também perdeu território para o Peru (AYALA, 1979).
} 
nos a questionar se as histórias, características, simbologias, fundamentos e significados encontram-se inseridos nos processos didático-pedagógicos das instituições de ensino formal dos respectivos países. Para refletir sobre essa questão, estabelecemos algumas sínteses que podem contribuir para a construção de uma ideia geral sobre a ineficácia das intenções dos postulados expressos em convenções, declarações, pactos, cartas de princípios em relação às manifestações populares.

A dificuldade para materializar algumas intenções pode ser explicada por dimensões históricas, políticas e sociais. Em vários países latino-americanos, as manifestações tradicionais que expressam a cultura de determinados povos autóctones ou de grupos étnicos submetidos a processos de exploração foram perseguidas e criminalizadas por dispositivos jurídicos, oficiais, legais, estatais, como se fossem moral e espiritualmente ilegítimas. A exemplos, temos a Capoeira (povo negro) no Brasil; o Juego del palin (povo Mapuche) no Chile; o Tinku (povo Ayllus) na Bolívia; a dança Montucuy (povo Zenú) e o Candombe (povo negro) no Uruguai; o Juego del tejo ou Turmequé (povo Chibcha), ambos na Colômbia.

Outras manifestações também foram proibidas sob o argumento de atentarem contra a moral e os bons costumes. Muitas dessas práticas carregam a marca da combinação de dor e prazer, tal como aludiu Paul Gilroy (2001), em relação às culturas produzidas pelos negros escravizados e seus descendentes. A sobrevivência dessas culturas só foi possível em virtude das particulares formas de adaptação às diversidades geopolíticas e, sobretudo, às formas de resistências contrahegemônicas.

Sobre essa questão, Certeau (1994) afirma que são as "táticas" de usos e resistências aos sistemas impostos que permitem que as culturas populares permaneçam vivas. Em visita à vários países latino-americanos e um 'mergulho' no cotidiano de algumas comunidades, o autor identificou haver uma relação de "estratégias" e "táticas" empreendida pelos sujeitos no dia a dia de suas ações. As estratégias correspondem a algum tipo de poder que "[...] postula um lugar capaz de ser circunscrito como um próprio e, portanto, capaz de servir de base a uma gestão de suas relações com uma exterioridade distinta" (CERTEAU,1994, p. 46).

Em contraponto, as táticas são as ações desviacionistas de subversão às normas impostas pelas estratégias, que visam controlar, mapear e impor. As táticas originam diferentes maneiras de fazer e consumir culturas. São resultados das astúcias e capacidades inventivas dos sujeitos, como formas de 'escapar' ao controle e à dominação. Em geral essas ações possibilitam sutis vitórias dos 
'fracos' sobre os 'mais fortes', pequenos sucessos ou golpes que denotam, de certa maneira, as resistências dos "modos de ser" e "de fazer" dos indivíduos e suas culturas (CERTEAU, 1994).

As constatações desse autor nos possibilitam compreender as inventividades dos sujeitos ante as estratégias legais impostas e ao consumo passivo dos mecanismos de controle e dominação. Essas ações não se percebem pelas formas acadêmicas, marginais ou populares, imaginárias ou políticas da cultura. Elas são percebidas pela sua operacionalidade nas práticas correntes do cotidiano. Apesar de guardarem marcas da exploração de classe, também resistem aos mecanismos da catequese cultural e da dominação, aos quais são submetidas nos diferentes contextos da sua produção.

Apesar dessas constatações, a possível ausência de políticas públicas eficazes e permanentes que envolvam as culturas populares dificulta o seu tratamento nos currículos de formação profissional e nos processos de escolarização, assim como em outros espaços nãoformais de educação. Nas últimas décadas, muitas expressões de culturas populares foram declaradas oficialmente como símbolos nacionais. Mesmo assim, a repressão, a perseguição e a proibição histórica dessas manifestações contribuíram para a invisibilidade e depreciação dessas culturas e, consequentemente, de seus praticantes.

Tais processos comprometem a democratização cultural no contexto dos países latinoamericanos. Eles inibem ou mesmo inviabilizam a criação, a ampliação e a proliferação de espaços e movimentos públicos que sejam plurais, informais e descontínuos para além do 'oficial' e do convencional. Além disso, a ausência de ações concretas que efetivem a proteção e a produção cultural favorece o que Fraser (2010) chama de "subordinação social de status", ou seja, o Estado, ao apoiar determinadas manifestações proclamadas como de "status superior", impede ou dificulta o usufruto do direito dos cidadãos das classes populares a manifestarem-se culturalmente. Com isso, privam-se os sujeitos e as comunidades de se expressarem e perpetuarem suas diferenças, saberes e maneiras de ser.

Fraser (2010) sugere que a paridade almejada e a política de reconhecimento sejam realizadas por intermédio, não de reconhecimento de identidades, mas via "reparações institucionais para danos institucionalizados”. Segundo a autora, “[ ... o não-reconhecimento não é nem uma deformação física, nem um dano cultural independente, mas uma relação institucionalizada de subordinação social” (FRASER, 2010, p. 121). Para ela, a invisibilização, ou o não-reconhecimento é, antes de tudo, a negação do status de parceiro integral, na interação social. 
Isso decorre de padrões institucionalizados de valoração cultural codificados na forma de leis ou via políticas governamentais que estigmatizam as diferenças e colocam pessoas, grupos e processos identitários em situação de subordinação institucionalizada de status social e impedem, assim, a efetiva paridade de participação. Nesse contexto, a alguns grupos culturais essa condição é negada.

Promover uma justiça cognitiva implica modificar os valores que regulam a interação social pelo fortalecimento de novos padrões institucionalizados de valor que, efetivamente, sejam capazes de garantir a paridade de participação na vida social. Essa mudança de valores passa pelo reconhecimento de que as culturas populares estão vinculadas a uma estrutura social mais ampla. Se o status e a estrutura econômica interpenetram-se, o processo de reparação da injustiça cognitiva passa pelo enfrentamento de uma injustiça distributiva. Sendo assim, a reivindicação pelo reconhecimento da inserção das culturas populares nos currículos de formação de educadores, requer o enfrentamento, via processos democráticos de justificativa pública, que evite o “[...] monólogo autoritário das políticas de autenticidade" (FRASER, 2010, p. 127).

Ao analisarmos os currículos de formação profissional no campo da Educação Física ${ }^{19}$ dos países investigados, constatamos uma discreta presença de manifestações das culturas populares, o que reforça o processo de invisibilização dessas práticas. Da mesma forma, não identificamos a presença das manifestações culturais apontadas por nosso levantamento nas grades curriculares analisadas. De maneira contraditória, encontramos os termos futebol, basquete, voleibol, rugby, e hockey, como indicação de conteúdo em mais de uma disciplina. Essa constatação no leva a questionar o motivo de El Tejo, Resfalosa, Juego del Palin, Joropo, Karabotas entre outros não estarem especificados nos currículos.

Com base nessa questão, ratificamos a necessidade de ampliação das abordagens epistemológicas para além das epistemes hegemônicas de heranças europeia e norte-americana para, então, reconstruir uma Educação Física latino-americana vinculada aos saberes/fazeres locais, institucionalmente invisibilizados. Ainda que uma prática cultural não carregue, ad infinitum, os mesmos fundamentos, intencionalidades e princípios que a geraram, a presença de disciplinas no currículo que dialoguem que a temática cultural popular pode possibilitar a construção de um contra-discurso bastante útil no enfrentamento a processos hegemônicos de dominação cultural,

\footnotetext{
19 Analisamos os currículos dos cursos de formação em Educação Física, dada a especificidade dessa área de conhecimento que lida com as manifestações culturais expressas pelas práticas corporais, como danças, lutas, jogos, esportes e ginásticas. Consideramos ser esta, uma área de mediação profissional importante para a promoção e valorização das culturas populares no âmbito das instituições educacionais.
}

Rev. Iberoam. Patrim. Histórico-Educativo, Campinas (SP), v. 5, p. 1-24, e019038, 2019. 
subordinação a interesses exógenos e a silenciamentos, que se materializam formal e institucionalmente, por via dos programas curriculares.

Por fim, é preciso resistir também, ao "etnocídio", bem como à "etnobiopirataria” em que universidades e empresas aliadas se envolvem com coleta de dados, informações, amostras de extratos, junto às comunidades locais, tanto rurais (camponesas, quilombolas, indígenas, pescadoras, ribeirinhas etc.), quanto urbanas, e os enviam para laboratórios e centros de pesquisas dos países do 'Primeiro Mundo'. Os benefícios desses saberes e os princípios ativos desses extratos são analisados e identificados para, posteriormente, serem patenteados e comercializados pelas grandes agências multinacionais. Essa apropriação indébita de um conhecimento coletivo não individualizável impede o reconhecimento dos direitos de propriedade das comunidades locais sobre seus saberes e conhecimentos habituais, já que elas não são portadoras do registro escrito, tampouco da certificação de suas fórmulas e receitas.

\section{CONSIDERAÇÕES FINAIS}

Conforme verificado nos documentos oficiais produzidos por representantes das cúpulas políticas dos países latino-americanos signatários de tratados internacionais, foram tomadas, nesse início do Século XXI, algumas iniciativas de promoção e apoio às culturas populares da América Latina, via convenções e tratados.

Entretanto, evidenciamos que, no cotidiano das classes populares, esses tratados não passam de preleções vazias que reforçam a injustiça social, com discursos que não se reverberam na prática, mas acenam para uma necessária articulação entre políticas públicas, sistemas educacionais e organizações não governamentais.

No plano legal, apesar de percebermos avanços no contexto das discussões acerca do reconhecimento da diversidade de produções, ainda predomina a ausência de ações comprometidas com a proteção e a promoção das culturas populares. Entendemos que a valorização dessas manifestações passa pela desburocratização de processos que viabilizem recursos materiais para a sua salvaguarda e expansão do patrimônio histórico-cultural. Assegurar essas condições favorece o fortalecimento e a democratização das culturas populares para que sobrevivam aos ensejos da indústria cultural. 
Sobre o papel das instituições formais de educação na promoção e valorização das culturas populares, destacamos a necessidade de maior empenho dessas instituições na diversificação dos conteúdos de ensino, com a inclusão de saberes oriundos das culturas populares nos currículos formativos.

No bojo dessas considerações, é essencial destacar que, para os grupos culturais existirem e se manterem na atualidade, devem ser garantidas condições materiais, financeiras e físicas. Suas premências culturais estão intimamente vinculadas e dependentes de outras necessidades imediatas, inerentes a todo e qualquer grupo social, como alimentação, habitação, saúde e assistência, renda digna, seguridade social, previdência pública etc. Não existindo as condições básicas, os direitos culturais são, em quaisquer circunstâncias, reduzidos à participação de alguns 'porta-vozes', em eventos e cerimônias de datas comemorativas.

Salientamos a necessidade de participação efetiva das próprias comunidades populares nos agenciamentos públicos que envolvem suas demandas específicas. Consideramos que a representação e a participação nas esferas de poder ainda precisam alcançar um patamar de envolvimento que assegure o cumprimento de acordos e de pactos traçados.

Por fim, almeja-se que os resultados dessas análises contribuam para a efetivação de políticas públicas consistentes e permanentes que promovam e preservem as expressões culturais populares forjadas pelas populações locais. É essencial a garantia de condições materiais de existência não só das culturas populares, mas, especialmente, dos responsáveis pela sua produção.

\section{REFERÊNCIAS}

AYALA, Alfredo. Geografía física general y especial de Bolivia. La Paz: Gisbert \& Cía, 1979. $329 \mathrm{p}$.

BARDIN, Laurence. Análise de conteúdo. Tradução de Luis Antero Reto e Augusto Pinheiro. Lisboa-Portugal: Edições 70/LDA, 1977. 225 p.

BRASIL. Constituição (1988). Constituição da República Federativa do Brasil. Brasília: Senado Federal, 1988.

CUNHA, Manuela, Carneiro da. Cultura com aspas e outros ensaios. São Paulo: Cosac Naify, 2009. $440 \mathrm{p}$. 
CARTA SUL-AMERICANA DAS CULTURAS POPULARES. 2008. Disponível em: http://culturadigital.br/setorialculturaspopulares/files/2010/02/2008-Carta-Sul-Americana-dasCulturas-Populares-Caracas-2008-Portugues-BR.pdf. Acesso em: 17 out. 2018.

CASTRO-GÓMEZ, Santiago. La poscolonialidad explicada a los niños. Popayán, Colômbia: Editorial Universidad del Cauca/Instituto Pensar, Universidad Javeriana, 2005.

CERTEAU, Michel de. A invenção do cotidiano: artes de fazer. Tradução de Ephraim Ferreira Alves. Petrópolis, RJ: Vozes, 1994. 351 p.

CONFERÊNCIA REGIONAL DAS AMÉRICAS SOBRE AVANÇOS E DESAFIOS NO PLANO DE AÇÃO CONTRA O RACISMO, A DISCRIMINAÇÃO RACIAL, A XENOFOBIA E AS INTOLERÂNCIAS CORRELATAS. Brasília, 2006. Disponível em: http://www.seppir.gov.br/central-de-conteudos/publicacoes/pub-assuntosinternacionais/relatorio_plenaria_final.pdf. Acesso em: 20 mar. 2018.

ENCONTRO SUL-AMERICANO DAS CULTURAS POPULARES = II SEMINÁRIO NACIONAL DE POLÍTICAS PðBLICAS PARA AS CULTURAS POPULARES, 1., 2006, Brasilia. Anais... Brasilia: Ministério da Cultura, Secretaria da Identidade e da Diversidade Cultural, 2006. 238 p.

FALCÃO, José Luiz Cirqueira et al. A presença da cultura popular nos currículos de formação profissional em Educação Física da Argentina, Chile, Colômbia e Peru. In: SILVA, Ana Márcia \& BEDOYA, Victor. Molina. (Orgs.). Educación Física en América Latina: currículos y horizontes formativos. Jundiaí-SP: Paco Editorial, p. 223-256, 2017.

FARIAS, Edson Silva de; MIRA, Maria Celeste. Introdução: mensagens do pós-nacionalpopular. In: FARIAS, Edson Silva de; MIRA, Maria Celeste. Faces contemporâneas da cultura popular. (Orgs.). Jundiaí: Paco Editorial, 2014.

FRASER, Nancy. Repensando o reconhecimento. Enfoques: Revista Eletrônica dos Alunos do PPGSA/ IFCS/ UFRJ, Rio de Janeiro, v. 9, n. 1, p. 114-128, 2010.

GALEANO, Eduardo. As veias abertas da América Latina. Rio de Janeiro: Paz e Terra, 2007. $384 \mathrm{p}$.

GEERTZ, Clifford. A interpretação das culturas. Rio de Janeiro: Guanabara, 1989. 470 p.

GILROY, Paul. O atlântico negro: modernidade e dupla consciência. Tradução de Cid Knipel Moreira. São Paulo: Ed. 34; Rio de Janeiro: Universidade Cândido Mendes, Centro de Estudos Afro-Asiáticos, 2001. 468 p.

HALL, Stuart. Da diáspora: identidades e mediações culturais. Belo Horizonte: Editora UFMG, 2006. 434 p. 
HARDT, Michael; NEGRI, Antonio. Multidão: guerra e democracia na era do império. Rio de Janeiro/São Paulo: Record, 2005. 532 p.

HENSBROEK, Pieter Boele Van. Cultural citizenship as a normative notion for activist practices. Citizenship Studies, v. 14, n. 3, p. 317-330, 2010.

II CONFERÊNCIA DE INTELECTUAIS DA ÁFRICA E DA DIÁSPORA. A diáspora e o renascimento africano. Relatório final. Brasília: Fundação Alexandre de Gusmão, 2009.

Disponível em: http://funag.gov.br/loja/download/549-ii CIAD.pdf Acesso em: 2 mar. 2018.

I ENCONTRO SUL-AMERICANO DAS CULTURAS POPULARES E II SEMINÁRIO NACIONAL DE POLÍTICAS PÚBLICAS PARA AS CULTURAS POPULARES. São Paulo: Instituto Polis; Brasília, DF: Ministério da Cultura, 2007.

INSTITUTO DO PATRIMÔNIO HISTÓRICO E ARTÍSTICO NACIONAL (IPHAN). Dossiê Iphan 12: Roda de capoeira e ofício dos mestres de capoeira. Brasília: Ministério da Cultura, 2008. Disponível em: http://portal.iphan.gov.br/uploads/publicacao/DossieCapoeiraWeb.pdf. Acesso em: 20 mar. 2018.

MENESES, Maria Paula. Justiça cognitiva. In: CATTANI, Antonio David; LAVILLE, JeanLouis.; GAIGER, Luiz Inácio; HESPANHA, Pedro (Org.). Dicionário Internacional da Outra Economia. Coimbra: Almedina, p. 231-236, 2009.

MIGNOLO, Walter. Histórias locais / projetos globais: colonialidade, saberes subalternos e pensamento liminar. Belo Horizonte: Editora UFMG, 2003. 505 p.

MORALES, Ghillermo. Abadía. Compendio general de folclore colombiano. 4. ed. rev. y acotada. Bogotá: Fondo de Promoción de la Cultura del Banco Popular, 1983. 541 p.

ONU. Declaração dos Direitos Humanos. 1948. Disponível em:

http://www.un.org/es/universal-declaration-human-rights/. Acesso em: 10 out. 2018. ONUBR. Organização Mundial da Propriedade Intelectual (OMPI). Disponível em: https://nacoesunidas.org/agencia/ompi/. Acesso em 19 out. 2018.

RANZI, Alceu. Universidade da floresta. In: Ambiente Acreano. 26 set. 2007. Disponível em: http://ambienteacreano.blogspot.com.br/2007/09/universidade-da-floresta_26.html. Acesso: 22 fev. 2018.

ROIZMAN, Maysa. Blay. A convenção sobre a proteção e promoção da diversidade das expressões culturais e o direito interno. In: PIDCC, Aracaju, Ano III, n. 5, p. 140-160, 2014.

SANTOS, Boaventura de Sousa. Para uma sociologia das ausências e uma sociologia das emergências. Revista Crítica de Ciências Sociais. n. 63. p. 237-280, 2002.

SANTOS, Boaventura de Sousa. Reconhecer para libertar: os caminhos do cosmopolitanismo multicultural. Rio de Janeiro: Civilização Brasileira, 2003, 610 p. 
SANTOS, Boaventura de Sousa; MENESES, Maria Paula. (Orgs.). Epistemologias do Sul. São Paulo: Cortez, 2009. 637 p.

SERRA, Ordep. VOLPINI, Lorena. Considerações sobre a violência fria. Caderno C R H. Salvador, v. 29, n. 76, p. 119-131, jan./abr. 2016.

SIL INTERNACIONAL. Associação Internacional de Linguística - Brasil. 2009. Disponível em: http://www-01.sil.org/americas/brasil/pdfs/2009-sil-update-portuguese.pdf. Acesso em: 30 out. 2018.

SILVA, Sidney de Souza. Danças tradicionais: elemento étnico-cultural de imigrantes bolivianos em São Paulo. In: FERNANDES, Joana.; HERBETTA, Alexandre. Ensaios sobre a diferença: reflexões a partir das culturas e identidades. Goiânia: CEGRAF - Gráfica da UFG, p. 67-80, 2016.

TORREALBA, Elvis Ramírez. Una aproximación histórica al desarrollo de la Educación Física en la América Prehispánica. In: Actas III Encuentro ALESDE Congreso Latinoamericano de Estudios Socioculturales del Deporte. Concepción, Chile, out. 2012.

UNESCO. Convenção sobre a proteção e promoção da diversidade das expressões culturais. 2007. Disponível em: http://unesdoc.unesco.org/images/0015/001502/150224POR.pdf. Acesso em: 19 out. 2018.

UNESCO. Patrimonio cultural inmaterial. Disponível em: https://ich.unesco.org/es/listas Acesso em: 20 out. 2018.

Recebido em: 12 de fevereiro de 2019 Aceito em: 29 de novembro de 2019 